\title{
4
}

\section{The Difference of Lectin Recovery by Sugar-Bound Resin}

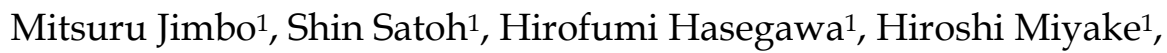 \\ Takao Yoshida2, Tadashi Maruyama ${ }^{2}$ and Hisao Kamiya ${ }^{1}$ \\ ${ }^{1}$ School of Marine Biosciences, Kitasato University \\ 2 Japan Agency for Marine-Earth Science and Technology \\ 1,2Japan
}

\section{Introduction}

Lectins are sugar binding proteins and glycoproteins, and are widely distributed from bacteria to humans. Lectins are easily detected by agglutination of erythrocytes, known as hemagglutination. Stillmark first reported in his doctoral thesis that the extract from beans of the castor tree, Ricinus communis, contains lectin by the method of hemagglutination (Stillmark, 1888). Since each lectin binds to a specific kind of sugar, and sugar chains on the cell surface differ according to cell type and animals species, lectins can distinguish types of cells (Landsteiner \& Raubitschek, 1907). Moreover, the lectin of red kidney beans has mitogenic activity, in which leucocytes are transformed into undifferentiated cells and initiate mitosis (Nowell, 1960). Thus, the lectins not only recognize specific cell types, but also affect cell physiology.

The lectins are defined as sugar binding proteins but are excluded from sugar binding antibodies and enzymes. They are classified into many groups based on amino acid sequences. For example, galectin, and C-type lectin are popular lectins (Kasai \& Hirabayashi, 1996; Drickamer, 1999), and even today, various lectins with new structures are still being found in many animals, bacteria, and fungi ( Jimbo et al., 2005; Tateno et al., 1998; Jimbo et al., 2000; Sato et al., 2011).

Lectins are involved in various biological phenomena such as self-defense (ficolins) (Matsushita, 2009), differentiation (Kawaguchi et al., 1991), and mineralization (Kamiya, et al., 2002). Self-defense is a well-known function of animal lectins. Lectins in invertebrates' hemolymph recognize and inactivate infecting bacteria, viruses, and so on. We found lectin activity in the hemolymph of the deep-sea bivalve Calyptogena okutanii (Jimbo et al., 2009).

Purification of a lectin is usually carried out using sugar affinity chromatography, since they bind to specific sugars. The scheme of lectin purification was shown in Figure 1. When a lectin-containing extract was applied to a resin to which the specific sugar was bound, the lectin binds to the resin and other proteins do not. After washing the resin, proteins except the lectin is flowed through the resin and the lectin only remains to be bound to the resin. When the specific sugar containing buffer is applied to the resin, the lectin detaches from the resin and the purified lectin are obtained from extract. 

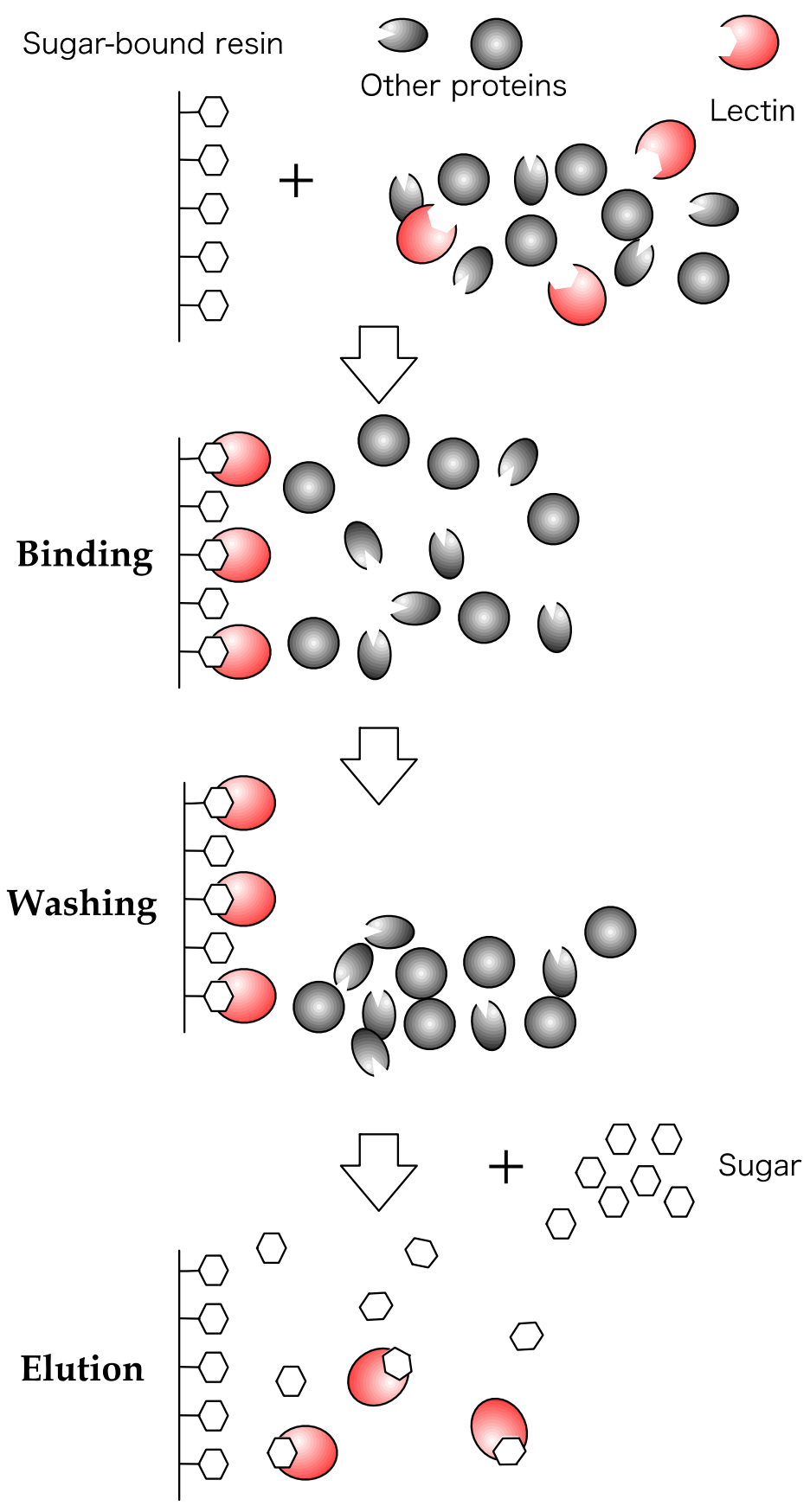

Fig. 1. A lectin purification scheme 


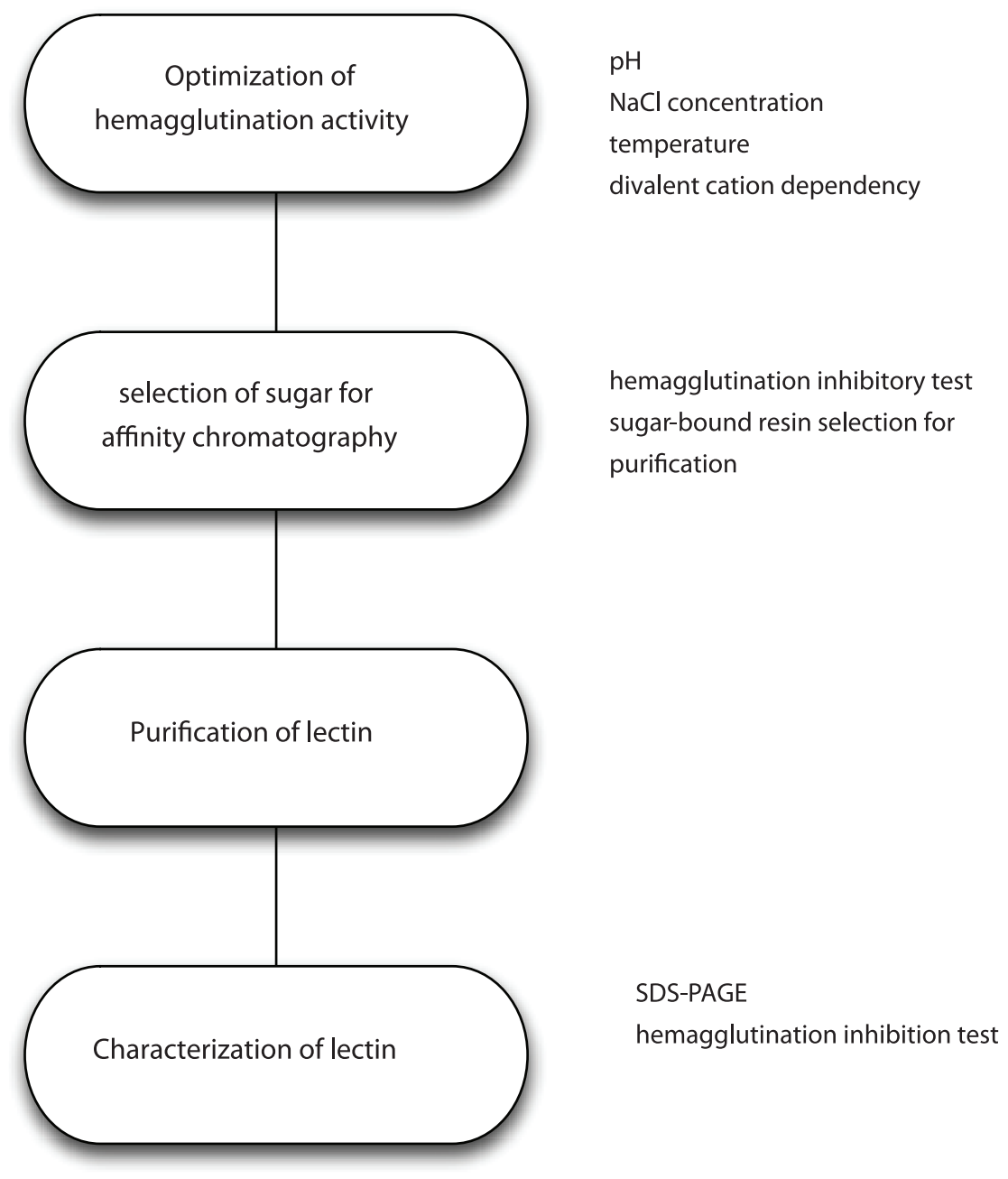

Fig. 2. A strategy of lectin purification

In the process of lectin purification, the usage of various types of resin results in drastically different lectin recovery with dissimilar properties of the purified lectin. In this chapter, we describe the optimal conditions for hemagglutination by lectin from C. okutanii, the employment of resin for lectin purification, and also the effects of resins on lectin recovery and the properties of the lectin (Fig. 2).

\section{Collection of hemolymph of Calyptogena okutanii}

Calyptogena okutanii belongs to the family Vesicomyidae and forms colonies at a depth of 750-2,100 m around Sagami Bay, Nankai Trough, and Okinawa Trough in Japan (Kojima \& Ohta, 1997; Fujikura et al., 2000). The habitat around C. okutanii is inclement: low 
temperatures of about $2^{\circ} \mathrm{C}$, lack of sunlight, and high pressure (more than $80 \mathrm{~atm}$ ). Thus, many animals including C. okutanii living in this habitat are supported by chemosynthesis. C. okutanii harbors symbiotic sulfur-oxidizing bacteria in their gill epithelial cells. As a consequence of the symbiosis with these bacteria, their digestive tracts are degenerated. It is interesting how their proteins have adapted to a habitat of high pressure and cold temperatures. Since we found hemagglutination activity in the hemolymph of C. okutanii, we tried to purify it to compare the protein structure of the lectin of a deep-sea chemosynthesis-based bivalve with those in other animals.

C. okutanii was collected using the remotely operated vehicle Hyper-Dorphine of the Japan agency of Marine Science and Technology (JAMSTEC) at NT08-03 and NT08-24 operation, or the submarine Shinkai 6500 of JAMSTEC at the YK05-12 operation. The sampling point was a seep off Hatsushima, Sagami Bay, at depth of $850 \mathrm{~m}\left(35^{\circ} 0.9441 \mathrm{~N}, 139^{\circ} 13.3181 \mathrm{E}\right)$. After collection, samples were kept at $4^{\circ} \mathrm{C}$ in filtrated sea water. Since C. okutanii and C. soyoae colonize together at the same place, the species of each bivalve was identified by sequence determination of the partial amplification of the cytochrome oxidase I gene (Folmeret al., 1994). The hemolymph was collected from the bivalve by cutting an adductor muscle using a scalpel, and was centrifuged at 2,000 rpm for $5 \mathrm{~min}$ at room temperature to remove blood cells. The supernatant was stored at $-80^{\circ} \mathrm{C}$ before use.

\section{Measurement of hemagglutination activity}

Lectins are easily detected by measuring hemagglutination activity, because sugar chains of peptidoglycans, extracellular matrix, glycoproteins, or glycolipids cover the cell surface of blood cells. However, the structure of sugar chains of blood cells is different from organism to organism. In addition, the incubation temperature and buffer composition employed are known to affect the lectin activity. Thus, we examined the optimal conditions for hemagglutination activity for C. okutanii hemolymph using various animal erythrocytes.

\subsection{Methods}

$4 \%$ animal erythrocyte suspensions were prepared as follows: Blood (chicken, guinea pig, goose, horse, bovine, sheep, rabbit, and human types $\mathrm{A}, \mathrm{B}, \mathrm{AB}$, and $\mathrm{O}$ ) was centrifuged at $2,000 \mathrm{rpm}$ for $5 \mathrm{~min}$ at room temperature. The pellet was resuspended with $50 \mathrm{ml}$ of $0.85 \%$ $\mathrm{NaCl}$, and the solution was centrifuged. After washing three times, the pellet was resuspended to make a $4 \%$ erythrocyte suspension.

The hemagglutination activity was measured as follows: A sample $(20 \mu \mathrm{l})$ was diluted by two-fold serial dilutions with dilution buffer $(600 \mathrm{mM} \mathrm{NaCl}, 20 \mathrm{mM}$ Tris- $\mathrm{HCl}, \mathrm{pH} 8.5,10$ $\mathrm{mM} \mathrm{CaCl} 2$ ) in a 96-well titerplate. After $20 \mu \mathrm{l}$ of $4 \%$ animal erythrocyte suspension was added to the dilution and mixed, the plate was incubated at $4^{\circ} \mathrm{C}, 25^{\circ} \mathrm{C}$, or $37^{\circ} \mathrm{C}$ for $30 \mathrm{~min}$. The hemagglutination activity (HU) was expressed as a titer defined as the reciprocal of the maximum dilution giving positive hemagglutination.

\subsection{Condition determination}

First, the hemagglutination activity was tested using several animal erythrocytes. As shown in Figure 3, only human erythrocyte suspensions gave high hemagglutination activities, 
while others gave less than one-tenth as much. The hemagglutination activity was not blood-type specific, and the differences in hemagglutination activity among blood types were small. So the hemagglutination activity of $C$. okutanii hemolymph was tested using human type A erythrocytes in following experiments.

Next, the effects of experimental conditions on hemagglutination activity were evaluated. We examined the effect of temperature on hemagglutination activity. The activity was the highest at $4^{\circ} \mathrm{C}$ and decreased at higher temperatures (Fig. 4A). For pH, the hemagglutination activity of $\mathrm{C}$. okutanii was the highest from $\mathrm{pH} 7.0$ to 9.0 and decreased at less than $\mathrm{pH} 7.0$ or at more than $\mathrm{pH} 9.0$ (Fig. 4B). The increase of $\mathrm{NaCl}$ concentrations resulted in higher hemagglutination activity. The activity increased up to $600 \mathrm{mM} \mathrm{NaCl}$, did not changed at higher concentrations (Fig. 4C).

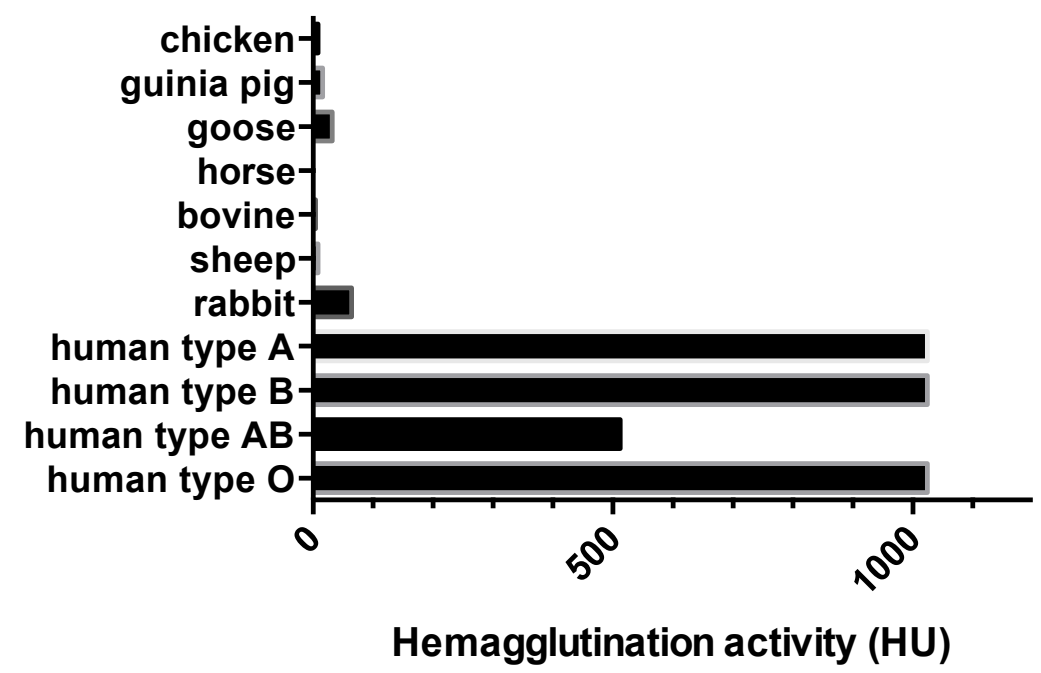

Fig. 3. Differences of hemagglutination activities of the C. okutanii hemolymph to various animal erythrocytes.

Divalent cations are important for the activity and structural stability of proteins, and some groups of lectins, like C-type lectins, need calcium ions for their activity (Drickamer, 1999). The hemagglutination activity of the hemolymph of C. okutanii also needs calcium ions. Interestingly, the hemagglutination activity showed a maximum titer at $10 \mathrm{mM} \mathrm{CaCl} 2$ and rapidly decreased at higher concentrations (Fig. 4D).

The concentrations of $\mathrm{NaCl}$ and $\mathrm{CaCl}_{2}$ in sea water are $600 \mathrm{mM}$ and $10 \mathrm{mM}$, respectively. $C$. okutanii lives at a depth of 750-2,100 m, and the composition of sea water is almost constant in the range of that depth, and the temperature at that depth is below $4^{\circ} \mathrm{C}$. This suggests that the lectin is adapted to the environment in which C. okutanii lives.

Given these results, the hemagglutination activity of $C$. okutanii hemolymph was measured at $4^{\circ} \mathrm{C}$ after dilution with $10 \mathrm{mM} \mathrm{CaCl}, 50 \mathrm{mM}$ Tris- $\mathrm{HCl}$, pH 8.5, $600 \mathrm{mM} \mathrm{NaCl}$, using $4 \%$ human type A erythrocyte suspension. 
A

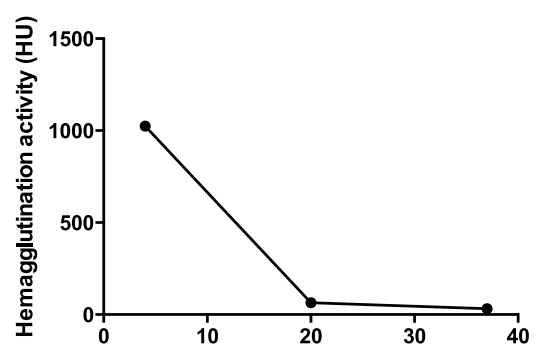

C

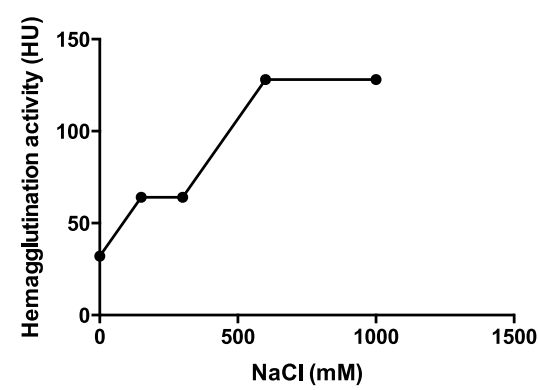

B

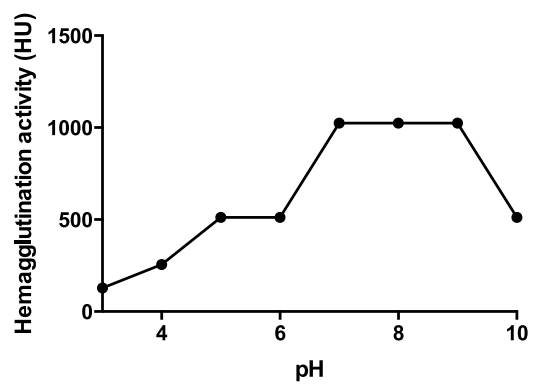

D

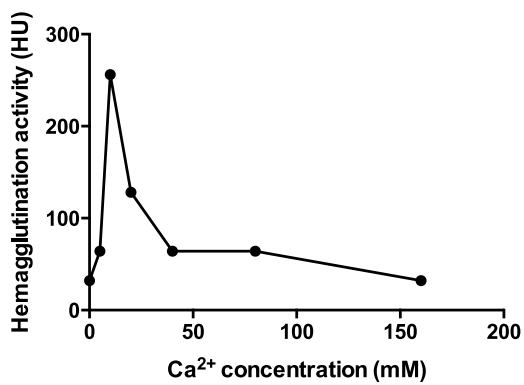

Fig. 4. Optimization of hemagglutination activity of the C. okutanii hemolymph.

The hemagglutination activity was measured by using different buffers for dilutions of hemolymph, or by using different incubation conditions. The hemagglutination test was conducted at 4,25 , and $37^{\circ} \mathrm{C}$ (A). For dilutions of hemolymph, solutions at different $\mathrm{pHs}$ containing a wide range buffers, glycine-acetate-MOPS $\mathrm{pH} 4,5,7,8,9$, 10, or phosphate buffer at $\mathrm{pH}$ 6.0, were used (B). $\mathrm{NaCl}$ concentrations of dilution buffers for hemolymph were 0,200 , 400, 600, and $1000 \mathrm{mM}$ (C). $\mathrm{CaCl}_{2}$ concentrations were $0,5,10,20,40,80$, and $160 \mathrm{mM}(\mathrm{D})$.

\section{Selection of sugars for affinity chromatography}

The determination of the sugar specificity of a lectin is needed to select the resin for using affinity purification. One test for determining sugar-binding specificity is the so-called hemagglutination inhibition test. A lectin is incubated with a sugar beforehand, and then the hemagglutination activity is examined. If the lectin has an affinity to the added sugar, hemagglutination is inhibited because the lectin already binds to the sugar. On the other hand, if the lectin does not have an affinity to the sugar, hemagglutination should occur. Using a variety of sugars, a sugar affinity profile of the lectin can be obtained.

\subsection{Methods}

$10 \mu \mathrm{l}$ of $0.2 \mathrm{M}$ sugars (D-glucose, D-glucosamine, $\mathrm{N}$-acetyl-D-glucosamine, D-galactosamine, $\mathrm{N}$-acetyl-D-glucosamine, D-galacturonic acid, L-arabinose, D-ribose, D-fucose, D-xylose, D- 
fructose, D-mannose, L-rhamnose, L-sorbose, $N$-acetyl-D-neuramic acid, maltose, lactose, or melibiose), or $0.5 \%$ of fetuin or mannnan were diluted with two-fold serial dilutions in a Vshaped 96-well titerplate. The hemagglutination titer of the hemolymph was adjusted to 16 $\mathrm{HU}$ by dilution with $600 \mathrm{mM} \mathrm{NaCl}, 10 \mathrm{mM} \mathrm{CaCl}_{2}, 50 \mathrm{mM}$ Tris- $\mathrm{HCl}, \mathrm{pH} 8.5 .10 \mu \mathrm{l}$ of the diluted hemolymph was added to the $\mathrm{V}$-shaped 96-well titerplate, and incubated at $4^{\circ} \mathrm{C}$ for $1 \mathrm{~h}$. After incubation, $20 \mu \mathrm{l}$ of $4 \%$ human type A erythrocyte suspension was mixed and incubated at $4^{\circ} \mathrm{C}$ for $30 \mathrm{~min}$. The result was expressed as the minimum inhibitory concentration of the sugar that completely inhibited hemagglutination.

\subsection{Hemagglutination inhibition of hemolymph}

The hemagglutination activity of hemolymph was inhibited by $\mathrm{N}$-acetyl neuramic acid (3.12 $\mathrm{mM}), N$-acetyl glucosamine $(6.25 \mathrm{mM}), N$-acetyl galactosamine $(12.5 \mathrm{mM})$, and D-glucosamine $(25 \mathrm{mM})$. Among the four inhibitory sugars, all except D-glucosamine share an $N$-acetyl group. It is expected that the lectin in the hemolymph can be purified using sugar-bound affinity chromatography using these sugars.

\subsection{Preparation of sugar-bound resins}

For lectin purification, many sugar-bound resins were used. To date, insoluble sugar polymers such as cellulose, dextran, or agarose (Ersson et al., 1973; Kamiya et al., 1988), glycoprotein-bound resin (Tunkijjanukij et al., 1997), and sugar-bound resin (Jimbo et al., 2007) have been used. To purify the hemolymph lectin, we chose to make a sugar-bound resin using epoxy-activated Sepharose 6B (GE healthcare Bioscience). The resin was prepared as follows: $3.6 \mathrm{~g}$ of epoxy-activated Sepharose $6 \mathrm{~B}$ was swelled with $500 \mathrm{ml}$ of distilled water, and was washed with $700 \mathrm{ml}$ of distilled water. After the addition of ligand solution $(20 \mathrm{mg} / \mathrm{ml} \mathrm{N}$-acetyl neuramic acid, $N$-acetyl glucosamine, $N$-acetyl galactosamine, or L-fucose at $\mathrm{pH} 13$ ), the Sepharose $6 \mathrm{~B}$ was incubated at $45^{\circ} \mathrm{C}$ for $20 \mathrm{~h}$ with shaking. The suspension was filtrated using a glass filter, and the Sepharose $6 \mathrm{~B}$ was collected. It was washed with $100 \mathrm{ml}$ of distilled water, $100 \mathrm{ml}$ of bicarbonate buffer $(500 \mathrm{mM} \mathrm{NaCl}, 100 \mathrm{mM}$ sodium bicarbonate, $\mathrm{pH} 8.0)$, and $100 \mathrm{ml}$ of acetate buffer $(500 \mathrm{mM} \mathrm{NaCl}, 100 \mathrm{mM}$ sodium acetate, $\mathrm{pH} 4.0$ ). The Sepharose $6 \mathrm{~B}$ was suspended with $100 \mathrm{ml}$ of $1 \mathrm{M}$ monoethanolamine, and incubated at $40^{\circ} \mathrm{C}$ for $16 \mathrm{~h}$, and then alternately washed with $100 \mathrm{ml}$ of acetate buffer and borate buffer $(0.5 \mathrm{M} \mathrm{NaCl}, 100 \mathrm{mM}$ borate, $\mathrm{pH} 8.0)$ three times. After washing, the resin was suspended in $10 \mathrm{mM} \mathrm{CaCl}_{2}, 600 \mathrm{mM} \mathrm{NaCl}, 50 \mathrm{mM}$ Tris- $\mathrm{HCl}, \mathrm{pH} 8.5$.

\subsection{Lectin binding to sugar-bound Sepharose 6B}

To confirm whether the hemolymph lectin was bound to the prepared sugar-bound Sepharose $6 \mathrm{~B}$, we examined whether the lectin was bound to the resin as follows. The sugar-bound resin $(100 \mu \mathrm{l})$ was transferred to a $1.5 \mathrm{ml}$ microtube and then washed with $1 \mathrm{ml}$ of the binding buffer $\left(10 \mathrm{mM} \mathrm{CaCl}_{2}, 600 \mathrm{mM} \mathrm{NaCl}, 50 \mathrm{mM}\right.$ Tris- $\mathrm{HCl}, \mathrm{pH}$ 8.5) three times. $100 \mu \mathrm{l}$ of the hemolymph was added to the washed sugar-bound resin, and incubated on ice for $1 \mathrm{~h}$ with occasional mixing. The tube was centrifuged at 5,000 rpm, at $4^{\circ} \mathrm{C}$ for $1 \mathrm{~min}$, and the supernatant was transferred to a new tube. The hemagglutination activity of the supernatant was determined.

After the hemolymph of C. okutanii was incubated with $\mathrm{N}$-acetyl neuramic acid-bound Sepharose 6B, $N$-acetyl glucosamine-bound sepharose 6B, or $N$-acetyl galactosamine-bound 
Sepharose $6 \mathrm{~B}$, the supernatant of the mixtures had less than $10 \%$ of the hemagglutination activity of the hemolymph before incubation (Fig. 5). Bacause more than $90 \%$ of the lectin in the hemolymph was estimated to be bound to these sugar-bound resins, these resins can be used for the purification of hemolymph lectin. We selected $\mathrm{N}$-acetyl neuramic acid- and $\mathrm{N}$ acetyl glucosamine-bound Sepharose $6 \mathrm{~B}$ as candidate resins for affinity purification because of their effective lectin binding.

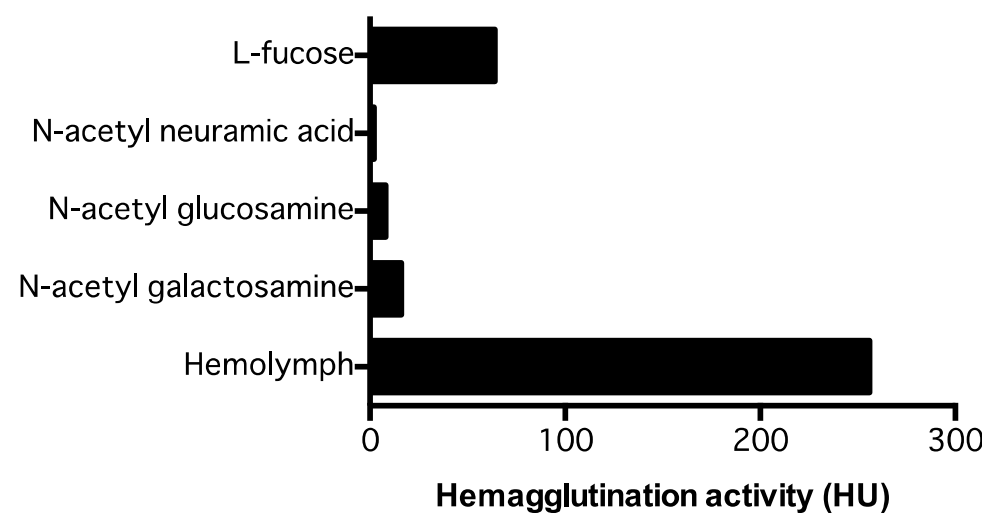

Fig. 5. Hemagglutination activity adsorption to sugar-bound resin.

The hemolymph was mixed with sugar-bound resin, and then the hemagglutination activity of the supernatant was measured. L-fucose, $N$-acetyl neuramic acid, $N$-acetyl glucosamine, and $\mathrm{N}$-acetyl galactosamine indicate L-fucose-, $\mathrm{N}$-acetyl neuramic acid-, $\mathrm{N}$-acetyl glucosamine-, and $\mathrm{N}$-acetyl galactosamine-bound Sepharose 6B, respectively. Hemolymph indicates that the hemagglutination activity was directly measured.

\section{Affinity purification of the hemolymph lectin by using sugar-bound resin}

The optimal condition for hemagglutination activity as described in Section 3 would be also suitable for affinity purification. The hemagglutination inhibition test and hemagglutination binding test to sugar-bound resin showed that the lectin in the hemolymph of C. okutanii can be purified by using $N$-acetyl neuramic acid- or $N$-acetyl-glucosamine-bound Sephrose 6B. In this section, we describe how the lectin was purified using these resins, and compare the activity recovery or property of each purified lectin.

\subsection{Methods}

$5 \mathrm{ml}$ of $\mathrm{N}$-acetyl neuramic acid-bound resin was equilibrated with binding buffer $(10 \mathrm{mM}$ $\mathrm{CaCl}_{2}, 600 \mathrm{mM} \mathrm{NaCl}, 50 \mathrm{mM}$ Tris- $\mathrm{HCl}, \mathrm{pH} 8.5$ ), and then $10 \mathrm{ml}$ of the hemolymph was applied to the resin. After washing with binding buffer, the bound lectin was eluted by elution buffer ( $40 \mathrm{mM} \mathrm{N}$-acetyl neuramic acid, $10 \mathrm{mM} \mathrm{CaCl}_{2}, 600 \mathrm{mM} \mathrm{NaCl}, 50 \mathrm{mM}$ Tris$\mathrm{HCl}, \mathrm{pH}$ 8.5). In the case of using $\mathrm{N}$-acetyl glucosamine-bound sepharose $6 \mathrm{~B}$, the bound lectin was eluted by elution buffer containing $0.2 \mathrm{M} \mathrm{N}$-acetyl glucosamine instead of $40 \mathrm{mM}$ $\mathrm{N}$-acetyl neuramic acid. The eluate was dialyzed against the binding buffer overnight. 


\section{2 $\mathrm{N}$-acetyl neuramic acid-bound Sepharose 6B}

The chromatogram is shown in Figure 6. The hemagglutination activity was completely adsorbed to the $\mathrm{N}$-acetyl neuramic acid-bound Sepharose $6 \mathrm{~B}$, and a single peak of the hemagglutination activity was eluted by the addition of $40 \mathrm{mM} \mathrm{N}$-acetyl neuramic acid in the binding buffer. After dialysis against the binding buffer overnight, the recovery was only about $4 \%$ in terms of hemagglutination activity (Table 1). Prolonged dialysis decreased hemagglutination activity of the lectin. No other protein was eluted by $8 \mathrm{M}$ urea, indicating that all the lectin bound to the resin was eluted by $N$-acetyl neuramic acid. Although EDTA, which is a calcium chelator, or ethyleneglycol was used for elution of the lectin to improve the recovery of hemagglutination activity, the eluates by them showed no activity.

The purified lectin was analyzed by SDS-PAGE (Figure 7). Only one component with an apparent molecular mass of $42.5 \mathrm{kDa}$ was observed under reducing conditions, while three components with apparent molecular masses of 235, 208, and $114 \mathrm{kDa}$, respectively, were found under non-reducing conditions. This indicated that the lectin was composed of 6 or 3 subunits. The amino terminal amino acid sequence of the component was ENAXXIINIQCGYGAGCGAA. The lectin eluted with $N$-acetyl neuramic acid was named as COL-N.
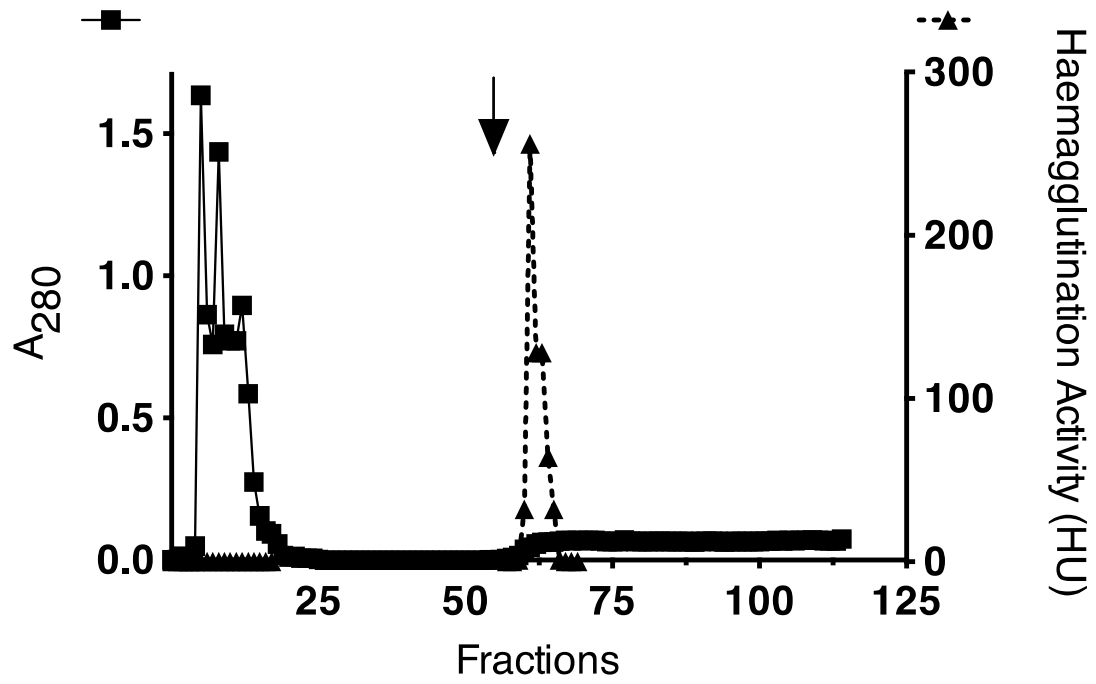

Fig. 6. Affinity purification using $N$-acetyl neuramic acid-bound resin.

The arrow indicated the addition of elution buffer. Closed squares and closed triangles indicate absorbance at $280 \mathrm{~nm}$ and hemagglutination activity, respectively.

\begin{tabular}{|c|c|c|c|c|c|}
\hline & $\begin{array}{c}\text { Protein } \\
(\mathrm{mg})\end{array}$ & $\begin{array}{c}\text { Total activity } \\
\text { (total HU) }\end{array}$ & $\begin{array}{c}\text { Recovery } \\
(\%)\end{array}$ & $\begin{array}{c}\text { Specific activity } \\
(\mathrm{HU} / \mathrm{mg} \text { protein })\end{array}$ & $\begin{array}{c}\text { Purification } \\
(\text { Fold })\end{array}$ \\
\hline Hemolymph & 222.3 & 307.2 & & 1.38 & 1 \\
\hline COL-N & 0.0624 & 12.2 & 3.96 & 196 & 142 \\
\hline
\end{tabular}

Table 1. Purification of COL-N 
$\begin{array}{lll}M & 1 & 2\end{array}$

$\operatorname{Mr}(\mathrm{kDa})$

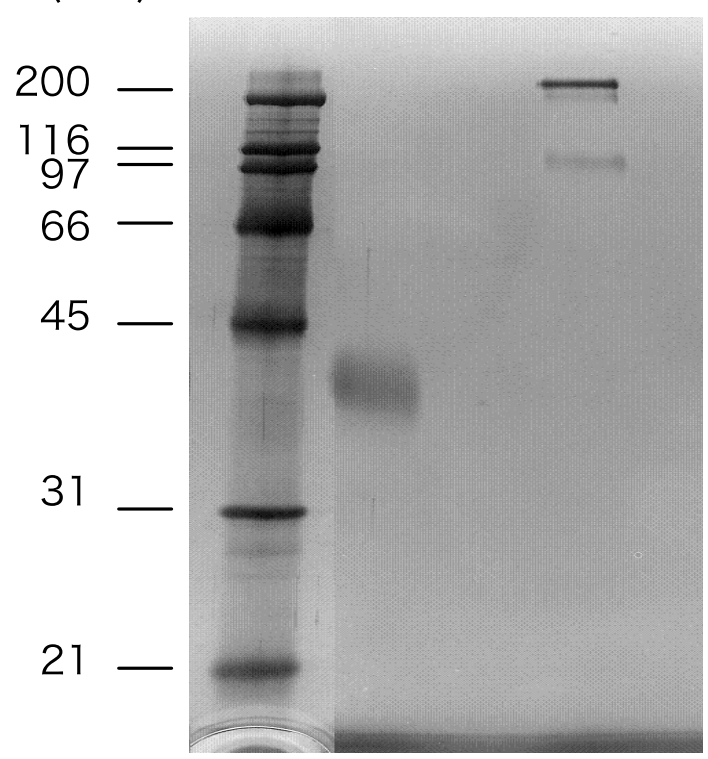

Fig. 7. SDS-PAGE of purified lectin

The purified lectin was analyzed by SDS-PAGE under reducing conditions (lane 1) or nonreducing conditions (lane 2). $\mathrm{M}$ indicates molecular standard proteins.

\subsection{N-acetyl glucosamine-bound Sepharose 6B}

When the lectin was eluted with $N$-acetyl glucosamine-bound resin, the hemagglutination activity was eluted by $\mathrm{N}$-acetyl glucosamine. The chromatogram of this purification was similar to that using $N$-acetyl neuramic acid, but the recovery of hemagglutination activity using $\mathrm{N}$-acetyl glucosamine-bound Sepharose 6B was much higher (Table 2). SDS-PAGE showed that the eluted peak was a single component with an apparent molecular mass of $42.5 \mathrm{kDa}$, similar to COL-N. Moreover, the amino terminal amino acid sequence of the lectin was identical to that of COL-N. So the lectin purified with $\mathrm{N}$-acetyl glucosamine was named as COL-G. These results indicated that COL-N and COL-G were identical. However, the recovery of COL-G activity was drastically different. The recovery of hemagglutination activity of COL-G was as high as $85 \%$ and was about 24 times higher than that of COL-N. Moreover, the specific activity of COL-G was also higher than that of COL-N.

\begin{tabular}{|c|c|c|c|c|c|}
\hline & $\begin{array}{c}\text { Protein } \\
(\mathrm{mg})\end{array}$ & $\begin{array}{c}\text { Total activity } \\
\text { (total HU) }\end{array}$ & $\begin{array}{c}\text { Recovery } \\
(\%)\end{array}$ & $\begin{array}{c}\text { Specific activity } \\
(\mathrm{HU} / \mathrm{mg} \text { protein })\end{array}$ & $\begin{array}{c}\text { Purification } \\
(\text { Fold })\end{array}$ \\
\hline Hemolymph & 518 & 443 & & 0.86 & 1 \\
\hline COL-G & 1.24 & 384 & 85 & 310 & 360 \\
\hline
\end{tabular}

Table 2. Purification table of COL-G 


\subsection{Sugar Inhibition profiles of COL-N and COL-G}

We characterized the properties of COL-N and COL-G. Their optimal hemagglutination activities were the same as those of the hemolymph with regard to $\mathrm{pH}, \mathrm{Ca}^{2+}$ concentration, and $\mathrm{NaCl}$ concentration. However, the hemagglutination inhibition profiles of these lectins were different (Table 3). The hemagglutination activity of COL-G was inhibited by D-glucosamine, $\mathrm{N}$-acetyl glucosamine, $\mathrm{N}$-acetyl galactosamine, and $\mathrm{N}$-acetyl neuramic acid. The minimum inhibitory concentrations of these sugars to the hemagglutination activity of COL-G were identical to that of the hemolymph. On the other hand, the hemagglutination activity of COL$\mathrm{N}$ was inhibited by D-glucosamine, $\mathrm{N}$-acetyl glucosamine, and $\mathrm{N}$-acetyl galactosamine like COL-G and the hemolymph of C. okutanii. However, the minimum inhibitory concentrations of these sugars to COL-N were two or four times higher than those to COL-G and the hemolymph. Moreover, the hemagglutination activity of COL-N was not inhibited by $\mathrm{N}$-acetyl neuramic acid, even at a concentration of less than $100 \mathrm{mM}$, although the minimum inhibitory concentration of $\mathrm{N}$-acetyl neuramic acid to the hemolymph was $3.12 \mathrm{mM}$.

\begin{tabular}{|c|c|c|c|}
\hline \multirow{2}{*}{ Sugars } & \multicolumn{4}{|c|}{ Minimum inhibitory concentration (mM) } \\
\cline { 2 - 4 } & hemolymph & COL-G & COL-N \\
\hline D-glucose & $-*$ & - & - \\
\hline D-glucosamine & 25 & 25 & 100 \\
\hline N-acetyl-D-glucosamine & 12.5 & 12.5 & 25 \\
\hline D-galactose & - & - & - \\
\hline D-galactosamine & - & - & - \\
\hline N-acetyl-D-galactosamine & 6.25 & 6.25 & 25 \\
\hline D-galacturonic acid & - & - & - \\
\hline L-arabinose & - & - & - \\
\hline D-ribose & - & - & - \\
\hline D-fucose & - & - & - \\
\hline D-xylose & - & - & - \\
\hline D-fructose & - & - & - \\
\hline D-mannose & - & - & - \\
\hline L-rhamnose & - & - & - \\
\hline L-sorbose & - & - & - \\
\hline N-acetyl-D-neuramic acid & 3.12 & 3.12 & - \\
\hline Maltose & - & - & - \\
\hline Sucrose & - & - & - \\
\hline Lactose & - & - & - \\
\hline Melibiose & - & - & - \\
\hline Fetuin & - & - & - \\
\hline mannan & - & - & - \\
\hline
\end{tabular}

* Hemagglutination activity was not inhibited at less than $100 \mathrm{mM}$.

Table 3. Sugar Inhibition Test

Our hypothesis to explain these results is that the lectin COL-N tightly binds to $N$-acetyl neuramic acid. In affinity chromatography, lectins are adsorbed to a sugar-bound resin, and then eluted by a sugar that is identical to the sugar bound to the resin. Thus, the lectin forms a complex with the sugar. The sugar bound to the lectin is usually removed by dialysis, but 
this is difficult if the lectin is strongly bound to the sugar. COL-N was purified with $N$-acetyl neuramic acid-bound Sepharose 6B, which was the strongest inhibitor of the hemagglutination activity of the hemolymph among the sugars tested. Thus, it is possible that COL-N remains bound to $\mathrm{N}$-acetyl neuramic acid and that overnight dialysis does not remove it. It is also possible that some of the lectins in the hemolymph that have affinity to $\mathrm{N}$-acetyl neuramic acid remain bound to the resin after elution. But no protein was eluted by $8 \mathrm{M}$ urea. It thus seems that no part of lectin bound to $\mathrm{N}$-acetyl neuramic acid remained to be adsorbed to the resin.

If COL-N binds to $\mathrm{N}$-acetyl neuramic acid, why did COL-N show hemagglutination activity in our experiments? One hypothesis is that there are two subunits that have different sugar binding affinities. As shown above, C. okutanii lectin is composed of 3 or 6 subunits. When the C. okutanii lectin was treated with glycopeptidase F, which removes sugar chains from $\mathrm{N}$ glycosylated proteins, C. okutanii lectin became two components with apparent molecular masses of 32.7 and $34.6 \mathrm{kDa}$ (data not shown), suggesting that $C$. okutanii lectin is composed of two different subunits. Since the amino terminal amino acid sequences of the two components were identical over 20 amino acid residues, each subunit must be closely related.

There are lectins that have a high similarity to each other, but their sugar binding profiles are different. Ficolins are serum lectins and are components of the innate immune system. Ficolin homologues are widely distributed in the animal kingdom (Lu \& Le, 1998). Mice have two ficolins, ficolin A and ficolin B (Endo et al., 2005). The amino acid sequences of these lectins have high identity to each other $(69 \%)$, but their sugar binding affinities are different. Ficolin A binds to $\mathrm{N}$-acetyl glucosamine and $\mathrm{N}$-acetyl galactosamine, while ficolin B binds to $\mathrm{N}$-acetyl glucosamine, $\mathrm{N}$-acetyl galactosamine, and $\mathrm{N}$-acetyl neuramic acid. The sugar binding properties of the C. okutanii lectin subunits may be similar to those of ficolins. If we hypothesize that $C$. okutanii lectin is composed of two subunits like mouse ficolins, and that one has high affinity to $\mathrm{N}$-acetyl neuramic acid while the other does not, the fact that COL-N has no affinity to $N$-acetyl neuramic acid can be explained as follows. In the case of COL-N, one subunit of the C. okutanii lectin is occupied by $N$-acetyl neuramic acid, while the other can still bind to $\mathrm{N}$-acetyl glucosamine and $\mathrm{N}$-acetyl galactosamine. The low recovery of the hemagglutination activity of COL-N is explainable assuming that COL-N is a complex with $\mathrm{N}$-acetyl neuramic acid. If COL-N binds to $\mathrm{N}$-acetyl neuramic acid, the total binding sites of COL-N should decrease, and the hemagglutination activity should also decrease.

\section{Conclusion}

For the purification of C. okutanii hemolymph lectin, $N$-acetyl neuramic acid-bound Sepharose 6B was poorly effective, and the properties of C. okutanii lectin were different from those of native lectin. When we used $N$-acetyl glucosamine-bound resin, the recovery of the lectin activity was $85 \%$, and the sugar-binding property of the purified lectin was identical to that of the hemolymph. When a sugar that strongly binds to a lectin is used as an affinity resin, it is possible that the lectin is not well recovered. On the other hand, when a sugar that binds weakly to the lectin is used, the lectin bound to the resin is small and much of it is unbound, resulting in low recovery. To purify lectin effectively with its natural properties, careful selection of sugar-bound resin is important. 
Moreover, this method is also applied to the others purified by affinity chromatography. To purify enzymes or cells with native activity, they can be purified by the affinity chromatography and it is possible that the activity of something purified is different from that of crude extract. Using a different resin for the purification, something purified with native activity can be obtained.

\section{Acknowledgments}

We thank the operating teams of the remotely operating vehicle Hyper-dorphine and the submarsible Shinkai 6500, and the crews of the research vessels Natsushima and Yokosuka that were used to collect $C$. okutanii specimens.

\section{References}

Drickamer, K. (1999). C-type lectin-like domains Current opinion in structural biology, Vol. 9, No.5, pp. 585-590

Endo, Y., Nakazawa, N., Liu, Y., Iwaki, D., Takahashi, M., Fujita, T., Nakata, M., et al. (2005). Carbohydrate-binding specificities of mouse ficolin A, a splicing variant of ficolin $A$ and ficolin B and their complex formation with MASP-2 and sMAP Immunogenetics, Vol. 57, No. 11, pp. 837-844.

Ersson, B., Aspberg, K., \& Porath, J. (1973). The phytohemagglutinin from sunn hemp seeds (Crotalaria juncea). Purification by biospecific affinity chromatography. Biochimica et biophysica acta, Vol. 310, No. 2, pp. 446-452.

Folmer, O., Black, M., Hoeh, W., Lutz, R., \& Vrijenhoek, R. (1994). DNA primers for amplification of mitochondrial cytochrome c oxidase subunit I from diverse metazoan invertebrates. Molecular marine biology and biotechnology, Vol. 3, No. 5, pp. 294-299.

Fujikura, K., Kojima, S, \& Fujiwara, Y. (2000). New Distribution Records of Vesicomyid Bivalves from Deep-sea Chemosynthesis-based Communities in Japanese Waters. Japanese Journal of Malacology, Vol. 59, No. 2, pp. 103-121.

Jimbo, M., Koike, K., Sakai, R., Muramoto, K, \& Kamiya, H. (2005). Cloning and characterization of a lectin from the octocoral Sinularia lochmodes. Biochemical and biophysical research communications, Vol. 330, No. 1, 157-162.

Jimbo, M., Usui, R., Sakai, Ryuichi, Muramoto, Koji, \& Kamiya, Hisao. (2007). Purification, cloning and characterization of egg lectins from the teleost Tribolodon brandti. Comparative Biochemistry and Physiology Part B: Biochemistry and Molecular Biology, Vol. 147, No. 2, pp. 164-171.

Jimbo, M, Yamaguchi, M., Muramoto, K, \& Kamiya, H. (2000). Cloning of the Microcystis aeruginosa M228 lectin (MAL) gene. Biochemical and biophysical research communications, Vol. 273, No. 2, pp. 499-504.

Jimbo, M., Yoshida, T., Nogi Y. (2009) Characterization of Calyptogena okutanii and Bathymodiolus japonicas lectin, In: Cruise Report NT08-24. 10, Oct, 2011, Available from: http://docsrv.godac.jp/MSV2_DATA/23/NT08-24_all.pdf

Kamiya, H, Jimbo, M, Yako, H., Muramoto, K, \& Nakamura, O. (2002). Participation of the C-type hemolymph lectin in mineralization of the acorn barnacle Megabalanus rosa. Marine Biology, Vol. 140, No. 6, pp. 1234-1240. 
Kamiya, H, Muramoto, K, \& Goto, R. (1988). Purification and properties of agglutinins from conger eel, Conger Myriaster (Brevoort), skin mucus. Developmental and comparative immunology, Vol. 12, No. 2, pp. 309-318.

Kasai, K., \& Hirabayashi, J. (1996). Galectins: a family of animal lectins that decipher glycocodes. Journal of biochemistry, Vol. 119, No. 1, pp. 1-8.

Kawaguchi, N., Kawaguchi, N., Komano, H., Komano, H., Natori, S., \& Natori, S. (1991). Involvement of Sarcophaga lectin in the development of imaginal discs of Sarcophaga peregrina in an autocrine manner. Developmental Biology, Vol. 144, No. 1, pp. 86-93.

Kojima, Shigeaki, \& Ohta, S. (1997). Calyptogena okutanii n. sp., a Sibling Species of Calyptogena soyoae Okutani, 1957 (Bivalvia : Vesicomyidae). The Japanese journal of malacology. Venus, Vol. 56, No. 3, pp. 189-195.

Landsteiner, K., \& Raubitschek, H. (1907). Beobachtungen uber Hämolyse und Hämagglutination. Zbl. Bakt. I. Abt. Orig., pp. 600-607.

Lu, J., \& Le, Y. (1998). Ficolins and the fibrinogen-like domain. Immunobiology, Vol. 199, No. 2, pp. 190-199.

Matsushita, M. (2009). Ficolins: complement-activating lectins involved in innate immunity. Journal of innate immunity, Vol. 2, No. 1, pp. 24-32.

Nowell, P. C. (1960). Phytohemagglutinin: an initiator of mitosis in cultures of normal human leukocytes. Cancer research, Vol. 20, pp. 462-466.

Sato, Y., Hirayama, M., Morimoto, K., Yamamoto, N., Okuyama, S., \& Hori, K. (2011). High mannose-binding lectin with preference for the cluster of alpha1-2-mannose from the green alga Boodlea coacta is a potent entry inhibitor of HIV-1 and influenza viruses. The Journal of biological chemistry, Vol. 286, No. 22, pp. 19446-19458, ISSN 1083-351X

Stillmark, P. H. (1988). Über Ricin, ein giftiges Ferment aus den Samen von Ricinus comm. L. und einigen anderen Euphorbiaceen. (R. Kobert, Ed.). University of Dorpat, Estonia.

Tateno, H., Saneyoshi, A., Ogawa, T., Muramoto, K., Kamiya, H., \& Saneyoshi, M. (1998). Isolation and characterization of rhamnose-binding lectins from eggs of steelhead trout (Oncorhynchus mykiss) homologous to low density lipoprotein receptor superfamily. The Journal of biological chemistry, Vol. 273, No 30, pp. 19190-19197.

Tunkijjanukij, S., Mikkelsen, H. V., \& Olafsen, J. A. (1997). A heterogeneous sialic acidbinding lectin with affinity for bacterial LPS from horse mussel (Modiolus modiolus) hemolymph. Comparative Biochemistry and Physiology Part B: Biochemistry and Molecular Biology, Vol. 117, No. 2, pp. 273-286. 


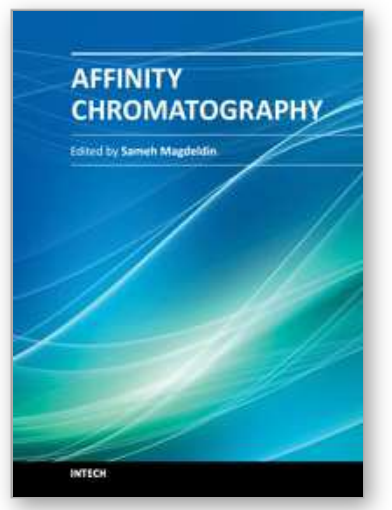

\author{
Affinity Chromatography \\ Edited by Dr. Sameh Magdeldin
}

ISBN 978-953-51-0325-7

Hard cover, 368 pages

Publisher InTech

Published online 21, March, 2012

Published in print edition March, 2012

Most will agree that one major achievement in the bio-separation techniques is affinity chromatography. This coined terminology covers a myriad of separation approaches that relies mainly on reversible adsorption of biomolecules through biospecific interactions on the ligand. Within this book, the authors tried to deliver for you simplified fundamentals of affinity chromatography together with exemplarily applications of this versatile technique. We have always been endeavor to keep the contents of the book crisp and easily comprehensive, hoping that this book will receive an overwhelming interest, deliver benefits and valuable information to the readers.

\title{
How to reference
}

In order to correctly reference this scholarly work, feel free to copy and paste the following:

Mitsuru Jimbo, Shin Satoh, Hirofumi Hasegawa, Hiroshi Miyake, Takao Yoshida, Tadashi Maruyama and Hisao Kamiya (2012). The Difference of Lectin Recovery by Sugar-Bound Resin, Affinity Chromatography, Dr. Sameh Magdeldin (Ed.), ISBN: 978-953-51-0325-7, InTech, Available from:

http://www.intechopen.com/books/affinity-chromatography/the-difference-of-lectin-recovery-by-sugar-boundresins-

\section{INTECH}

open science | open minds

\section{InTech Europe}

University Campus STeP Ri

Slavka Krautzeka 83/A

51000 Rijeka, Croatia

Phone: +385 (51) 770447

Fax: +385 (51) 686166

www.intechopen.com

\section{InTech China}

Unit 405, Office Block, Hotel Equatorial Shanghai

No.65, Yan An Road (West), Shanghai, 200040, China

中国上海市延安西路65号上海国际贵都大饭店办公楼 405 单元

Phone: +86-21-62489820

Fax: +86-21-62489821 
(C) 2012 The Author(s). Licensee IntechOpen. This is an open access article distributed under the terms of the Creative Commons Attribution 3.0 License, which permits unrestricted use, distribution, and reproduction in any medium, provided the original work is properly cited. 